\title{
Vapor Permeation of Bioethanol with Quaterinized Chitosan-Lipid Complex Membranes
}

\author{
Yuki Iwamoto' $^{1)}$, Takafumi Shimizu' ${ }^{1)}$, Yuya Murai ${ }^{1)}$, \\ Masakazu Yoshikawa ${ }^{1)}$, and Naoya Ogata ${ }^{2}$
}

1) Department of Biomolecular Engineering, Kyoto Institute of Technology, Matsugsaki, Kyoto 606-8585, Japan

2) Ogata Research Laboratory, Ltd., 1-3-1 Kashiwadai-minami, Chitose 006-0009, Japan

Membranes from quaterinized chitosan $(\mathrm{QCh})$, which was a derivative of marine (natural) polymer, and sodium 1dodecylsulfate (C12SNa) transported ethanol in preference to water by vapor permeation. Membrane performance, such as permselectivity and flux, was enhanced with the increase in amphiphile (C12S) content in the membrane. The results suggested that the QCh-C12S complex membranes were applicable to selective separation of bioethanol from fermentation broth.

Key words : bioethanol / chitosan / permselectivity / quaterinized chitosan / vapor permeation

\section{Introduction}

There are various polymeric materials, such as synthetic polymers and derivative of natural polymers, which are used as candidate materials for membranes $^{1}$. It is an interesting and an important subject to obtain membranes from natural polymers, in other words, environmentally-friendly 'green' polymers, or derivative of those. To this end, the authors' research group have been studying molecularly imprinted membranes from cellulose acetate ${ }^{2 \sim 4)}$ or proteins from Geobacillus thermodenitrificans DSM465 ${ }^{5,6)}$, pervaporation membranes from agar$o^{o s} \mathrm{e}^{7 \sim 9)}$, agarose/hydrophilic polymer ${ }^{10)}$, or agarose/ derivative of natural polymer ${ }^{11}$, and vapor permeation membranes from gelatin/polyamideimide ${ }^{12)}$ or $G$ thermodenitrificans DSM465/polyamideimide ${ }^{13)}$. Chiral separation was studied adopting egg shell membranes ${ }^{14)}$. DNA, which was considered as a polyanion with a huge molecular weight, was adopted as membrane materials and chiral separation ${ }^{15 \sim 17)}$ and selec-

* Corresponding Author

Tel: 075-724-7816

Fax: 075-724-7800

E-mail: masahiro@kit.ac.jp tive transport of oxygen with DNA complex membranes ${ }^{18)}$ were investigated. Contrary to this, polycation of natural polymer or derivative of that was also expected to give a chiral separation membrane. Quaterinized chitosan/lipid complex membranes, of course, showed chiral separation ability ${ }^{19}$.

Ion exchange membranes such as Nafion with metal cations from group 1, 2, and 13 of the periodic table ${ }^{20,21)}$ and sulfonated polyethylene with metal cations from group ${ }^{22)}$ always demonstrated selective transport of water from aqueous alcohol solutions (e.g. aqueous 2-propanol and aqueous ethanol) by pervaporation. Incorporation of hydrophobic organic counterions, such as quaternary ammonium cations with longer alkyl groups (butyl-octyl), changed the pervaporation performance of the ion exchange membranes ${ }^{23}$; in other words, instead of water, alcohol was transported in preference to water and the selectivity toward alcohol was correlated to the hydrophobicity of counter ions and alcohols. From this ${ }^{23)}$, membranes from quaterinized chitosan-lipid complexes are expected to show permselectivity toward alchol in separation of aqueous alcohol mixtures since they consisted of hydrophobic longer alkyl chains (dodecyl-hexadecyl) ${ }^{19)}$. Selective separation of alcohol is interesting and indispensable in connection with production of bio- 
fuels, which are produced via fermentation of biomass. To this end, in the present rapid communications, vapor permeation performance of bioethanol through membranes from quaterinized chitosan-lipid complexes was investigated. In the present study, aqueous ethanol solution was adopted as a model mixture of biofuel/water mixture.

\section{Experimental}

Quaterinized chitosan (QCh) with 2-hydroxypropyltrimethylammonium cationic charge sites, of which degree of quaterinization being 1.3, was kindly supplied by Dainichiseika Color \& Chemicals Mfg. Co. Ltd. and used as received. Anionic amphiphile, sodium 1-dodecansulfate (C12SNa), was used without further purification. Dimethylsulfoxide (DMSO) and ethanol were used without further purification. Water purified with an ultrapure water system (Simpli Lab, Millipores S. A., Molsheim, France) was used.

\section{QCh}

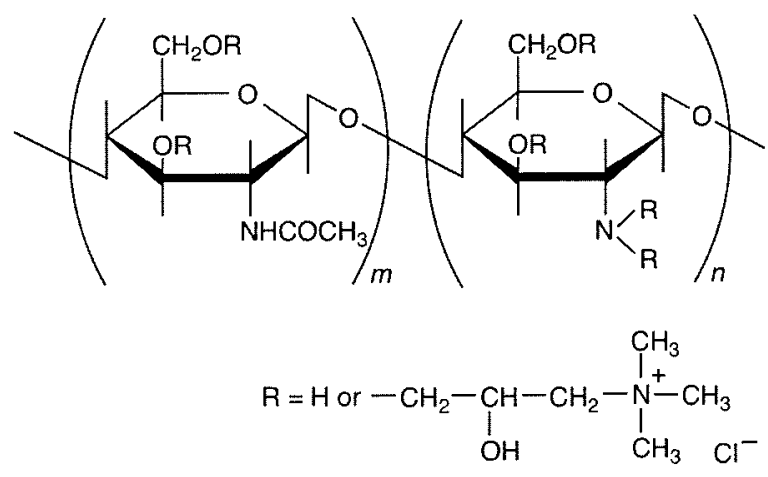

\section{C12SNa}

$$
\mathrm{CH}_{3}\left(\mathrm{CH}_{2}\right)_{11}-\mathrm{OSO}_{3}^{-} \mathrm{Na}^{+}
$$

The preparation of QCh-C12S complex is simple like that of DNA-lipid complex ${ }^{24,25)}$ : an aqueous solution of $\mathrm{QCh}$ and an aqueous $\mathrm{C} 12 \mathrm{SNa}$ one were mixed at ambient temperature. The precipitate was washed with water by centrifugation and dried in vacuo at $80^{\circ} \mathrm{C}$ for 1 d. Dimethylsulfoxide (DMSO) was adopted as a solvent for the $\mathrm{QCh}-\mathrm{C} 12 \mathrm{~S}$ complexes. The composition of $\mathrm{QCh}-\mathrm{C} 12 \mathrm{~S}$ complex was determined by using intensity of methyl protons for C12S (0.92 ppm) and that for QCh (3.17 ppm) in ${ }^{1} \mathrm{H}$ NMR spectra of QCh-C12S complexes, using DMSO- $\mathrm{d}_{6}$ as a deuterated solvent.

A $0.4 \mathrm{~g}$ of QCh-C12S complex was dissolved in $7.6 \mathrm{~g}$ of DMSO. The DMSO solution was poured into a TeflonPFA $75 \mathrm{~mm}$ diameter laboratory dish and the solvent was allowed to evaporate at $80^{\circ} \mathrm{C}$ for $24 \mathrm{~h}$. The thickness of the membrane, $\delta(\mathrm{m})$, was $76 \sim 83 \mu \mathrm{m}$, which were determined by using micrometer.

Vapor permeation experiments were carried out following the procedure described in the previous paper ${ }^{12}$. The performance of membranes was determined by the flux, $J\left(\mathrm{~kg} \mathrm{~m}^{-2} \mathrm{~h}^{-1}\right)$, and the separation

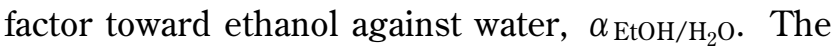
flux is defined as

$$
J=Q / A t
$$

where $Q(\mathrm{~kg})$ denotes the collected amount of the permeate, $A\left(\mathrm{~m}^{2}\right)$ is membrane area, and $t$ denotes time (h), respectively.

The separation factor $\alpha_{\mathrm{EtOH} / \mathrm{H}_{2} \mathrm{O}}$ is defined as

$$
\alpha_{\mathrm{EtOH} / \mathrm{H}_{2} \mathrm{O}}=\left(Y_{\mathrm{EtOH}} / Y_{\mathrm{H}_{2} \mathrm{O}}\right) /\left(X_{\mathrm{EtOH}} / X_{\mathrm{H}_{2} \mathrm{O}}\right)
$$

where $Y_{\mathrm{i}} \mathrm{s}$ are the weight fractions in permeate and $X_{\mathrm{i}} \mathrm{s}$ are those in vapors in feed, respectively.

\section{Results and Discussion}

As for the composition of the $\mathrm{QCh}-\mathrm{C} 12 \mathrm{~S}$ complex, the ratios of the amount of anionic site to that of cationic site $(-/+)$ for the $\mathrm{QCh}-\mathrm{C} 12 \mathrm{~S}$ complexes studied in the present study ranged from 1.12 to 1.56 . As reported previously ${ }^{19)}$, it was very hard to obtain a $\mathrm{QCh}-$ C12S complex with a prescribed composition. The composition of the formed complex was inclined to exceed the feed composition; in other words, the ratios of the amount of anionic site to that of cationic site in the complex preparation process were $0.90,1.00,1.10$ and 1.20 , respectively. And the ratios for the $\mathrm{QCh}-$ C12S complex were determined to be $1.12,1.25,1.40$, and 1.56, respectively. Some anionic amphiphiles were thought to be existed in QCh-lipid complex as a form of micell. It is an unsolved problem to obtain complexes with the prescribed ratio of sulfate anions to ammonium cations. In a future study, it is requisite to prepare QCh-lipid complexes below the critical micell concentration of around $7.22 \times 10^{-3} \mathrm{~mol} \mathrm{dm}^{-3}$ at ambient conditions ${ }^{26)}$.

The results of vapor permeation of aqueous ethanol solution with weight fraction of ethanol in the feed of 
Table 1 Results of vapor permeation of aqueous ethanol solution through the membranes

\begin{tabular}{|c|c|c|c|c|c|c|}
\hline$-1+$ & $\begin{array}{l}\text { Weight fraction of } \\
\text { EtOH in feed } \\
\text { liquid }\end{array}$ & $\begin{array}{l}\text { Weight fraction of } \\
\text { EtOH in feed } \\
\text { vapor }\end{array}$ & $\begin{array}{l}\text { Weight fraction of } \\
\text { EtOH in permeate }\end{array}$ & $\alpha_{\text {EFOHस2O }}{ }^{a}$ & $\mathrm{~J} / \mathrm{kg} \mathrm{m}^{-2} \mathrm{~h}^{-1}$ & $\delta / m$ \\
\hline 1.12 & 0.0947 & 0.4916 & 0.6023 & 1.6 & 2.8 & $83.1 \times 10^{-6}$ \\
\hline 1. 25 & 0.0922 & 0.4828 & 0.6558 & 2.0 & 3.4 & $82.8 \times 10^{-6}$ \\
\hline 1. 40 & 0.0939 & 0.4887 & 0.6873 & 2.3 & 4.3 & $79.8 \times 10^{-6}$ \\
\hline 1. 56 & 0.0943 & 0.4903 & 0.6971 & 2.4 & 6.1 & $76.1 \times 10^{-6}$ \\
\hline PDMS & 0.0958 & 0.4953 & 0.6546 & 1.9 & 1.0 & $76.2 \times 10^{6}$ \\
\hline
\end{tabular}

around 0.095 through the various $\mathrm{QCh}-\mathrm{C} 12 \mathrm{~S}$ membranes are summarized in Table 1 . In the present study, it was very hard to obtain an aliquot of the vapor equilibrated with the boiling feed solution. The composition of the feed vapor was determined by using the feed liquid composition, which was analyzed by a gas chromatography and vapor-liquid equilibrium data ${ }^{27}$. As expected, those four types of QCh-C12S complex membrane transported ethanol vapor in preference to water vapor like pervaporation of aqueous alcohol solution through Nafion with hydrophobic organic counterions ${ }^{23)}$. Both flux value and permselectivity toward ethanol increased with the increase in the amount of amphiphile molecule in the membrane. The permselectivity toward ethanol was thought to be expressed as follows: hydrophobic alkyl chains sorbed ethanol preferentially from feed vapor mixtures and ethanol was, as a result, selectively transported through the $\mathrm{QCh}-$ C12S complex membranes.

There were reported various alchol permeable membranes $^{28 \sim 37}$. Among those membranes, polydimethylsiloxane (silicone) membrane was perceived as a typical alchol permeable membrane ${ }^{28,29)}$. Vapor permeation performance of polydimethylsiloxane membrane, which was kindly supplied by General Electric Co., was also studied. As shown in Table 1, polydimethylsiloxane membrane transported ethanol preferentially from aqueous ethanol mixture not only by pervaporation but also vapor permeation. $\mathrm{QCh}-\mathrm{C} 12 \mathrm{~S}$ complex membranes with higher lipid content showed higher flux and permselectivity than polydimethylsiloxane membrane. The present results suggested that QCh-lipid complex membranes were applicable to separation of bioethanol from fermentation broth by vapor permeation.

\section{References}

1) Mulder M : "Basic Pribciples of Membrane Technology", Chap. 2, Kluwer Academic Publishers, Dordrecht (1996)

2) Izumi J, Yoshikawa M, Kitao T : Membrane, 22, 149-154 (1997)

3) Yoshikawa M, Ooi T, Izumi J :J. Appl. Polym. Sci., 72, 493-499 (1999)

4) Yoshikawa M, Izumi J, Guiver MD, Robertson GP : Macromol. Mater. Eng., 286, 52-59 (2001)

5) Yoshikawa M, Kawamura K, Ejima A, Aoki T, Sakurai S, Hayashi K, Watanabe K : Macromol. Biosci., 6, 210-215 (2006)

6) Yoshikawa M, Kawamura K, Watanabe, K : Membrane, 32, 40-44 (2007)

7) Yoshikawa M, Yoshioka T, Fujime J, Murakami A : J. Membr. Sci., 178, 75-78 (2000)

8) Masaki K, Yoshikawa M : Membrane, 26, 155-157 (2001)

9) Yoshikawa M, Masaki K, Ishikawa M : J. Membr. Sci., 205, 293-300 (2002)

10) Yoshikawa M, Yoshioka T, Fujime J, Murakami A : Membrane, 26, 259-264 (2001)

11) Yoshikawa M, Yoshioka T, Fujime J, Murakami A : J. Appl. Polym. Sci., 86, 3408-3411 (2002)

12) Yoshikawa M, Higuchi A, Ishikawa M, Guiver MD, Robertson GP : J. Membr. Sci., 243, 89-95 (2004)

13) Yoshikawa M, Kawamura K, Ejima A, Aoki T, Watanabe K, Guiver MD, Robertson GP : Membrane, 29, 384-387 (2004)

14) Kondo Y, Yoshikawa M : Membrane, 26, 228-230 (2001)

15) Yoshikawa M, Maruhashi M, Iwamoto Y, Ogata N : Macromol. Symp., 249-250, 557-561 (2007)

16) Yoshikawa M, Maruhashi M, Iwamoto $Y$, Ogata, $N$ : Polym. J., 39, 1193-1198 (2007)

17) Iwamoto $Y$, Maruhashi M, Yoshikawa M, Ogata N : Membrane, 34, 281-287 (2009)

18) Matsuura T, Sada T, Yoshikawa M, Ogata N : Membrane, 31, 281-283 (2006)

19) Iwamoto $Y$, Yoshikawa M, Yamaoka K, Ogata N : Desalination and Water Treatment, 17, 268-274,(2010)

20) Cabasso I, Liu Z-Z: J. Membr. Sci., 24, 101-119 (1985) 
21) Cabasso I, Liu Z-Z, Makenzie T : J. Membr. Sci., 28, 109122 (1986)

22) Cabasso I, Korngold E, Liu Z-Z : J. Polym. Sci., Polym. Lett. Ed., 23, 577-581 (1985)

23) Pasternak M, Dorawala TG : J. Polym. Sci., Part A: Polym. Chem., 29, 915-917 (1991)

24) Ijiro K, Okahata Y : J. Chem. Soc., Chem. Commun., 1339$1441(1992)$

25) Tanaka K, Okahata Y : J. Am. Chem. Soc., 118, 1067910683 (1996)

26) Ward AFH : Proc. Roy. Soc. Lond. A, 176, 412-427 (1940)

27) Gmegling J, Onken U, Rarey-Nies JR : "Vapor-liquid equilibrium data collection 1b", DECHEMA, Frankfurt (1988)

28) Kimura S, Nomura T : Membrane, 7, 353-354 (1982)

29) Kimura S, Nomura T : Membrane, 8, 177-183 (1983)

30) Ishihara K, Nagase Y, Matsui K : Makromol. Rapid Commun., 7, 43-46 (1986)

31) Masuda T, Tang B-Z, Higashimura T : Polym. J., 18, 565567 (1986)

32) Yoshikawa M, Yukoshi T, Sanui K, Ogata N, Shimidzu T : Membrane, 12 158-164 (1987)

33) Hennepe HJCte, Bargeman D, Mulder MHV, Smolders CA : J. Membr. Sci., 35, 39-55 (1987)

34) Miyata T, Takagi T, Uragami T : Macromolecules, 29 , 7787-7794 (1996)

35) Nomura M, Yamaguchi T, Nakao S : J. Membr. Sci., 144, 161-171 (1998)

36) Nagai K, Masuda T, Nakagawa T, Freeman BD, Pinnau I : Prog. Polym. Sci., 26, 721-798 (2001)

37) Sakaguchi T, Yumoto K, Shiotsuki M, Sanda F, Yoshikawa M, Masuda T : Macromolecules, 38, 2704-2709 (2005)

(Received 19 April 2010;

Accepted 8 June 2010) 